\title{
Research Paper: \\ The Effects of School-based Physical Exercise With Different Cognitive Loads on Executive Functions
}

\author{
Shohre Mardasangi Dulabi ${ }^{1}$ (D), Mohammadreza Ghasemian ${ }^{1^{*}}$ (D) Mohammadali Aslankhani $^{1}$
}

1. Department of Motor Behavior, Faculty of Physical Education and Sport Sciences, Allameh Tabataba'i University, Tehran, Iran

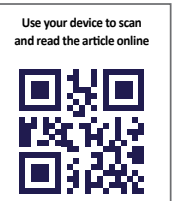

Citation Mardasangi Dulabi S, Ghasemian MR, Aslankhani MA. The Effects of School-Based Physical Exercise With Different Cognitive Loads on Executive Functions Journal of Exercise Science and Medicine. 2020; 12(1):47-56. http://dx.doi. org/10.32598/JESM.12.1.5

http://dx.doi.org/10.32598/JESM.12.1.5

Keywords:

Executive functions, Physical exercise, rehabilitation, Cognitive training

\section{A B S T RACT}

Introduction: The present study aimed to compare the effects of 3 school-based physical exercises with different levels of cognitive engagement on executive functions.

Materials and Methods: In total, 47 students aged 13-14 years were randomly divided into 3 groups, as follows: the Integrated Physical and Cognitive (IPC) exercise, peer physical exercise group (with the same physical challenge), and control group (the routine physical education program). A Continuous Performance Test (CPT), the N-back test, and the Stroop test were used to evaluate executive functions in pretest and posttest.

Results: The obtained results indicated that the IPC group significantly improved more than the other groups on the executive functions. Accordingly, physical exercise with a higher cognitive load benefitted both speed and accuracy on cognitive tasks significantly more than the same physical activity alone.

Conclusion: Therefore, in the integrated physical and cognitive exercise, the cognitive and physiological effects of this training style interact with each other; therefore, their beneficial effects can be gradually increased, while interventions that only focus on the physical dimension would be less effective in promoting cognitive functions.

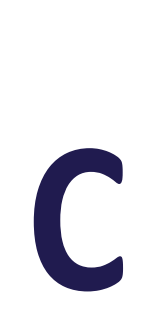

\section{Introduction}

ognitive functions play an essential role in improving the quality of life. These functions include distinct but interrelated processes, i.e., responsible for controlling and organizing goal-directed behaviors [1]. The executive functions are critical cognitive functions and include self-control, selective attention, working memory, and cognitive flexibility. Optimal levels of these functions significantly impact individuals' health, job success, academic achievement, and other important facets of life [2]. Executive functions continue to improve throughout adolescence [3]. Accordingly, adolescence is a crucial and significant period for studying executive functions [4]. Several studies investigated factors affecting executive functions. Various interventions were used to optimize them, in-

* Corresponding Author:

Mohammadreza Ghasemian, PhD.

Address: Department of Motor Behavior, Faculty of Physical Education and Sport Sciences, Allameh Tabataba'i University, Tehran, Iran

Tel: +98 (21) 48394132

E-mail: mor.ghasemian@atu.ac.ir 
cluding physical exercise, cognitive training, and neuropsychological interventions, including brain stimulation, and so on [5-7]. Some of these interventions, like physical activity related to lifestyle changes, have received more attention in recent decades $[8,9]$. School-Based physical training is a common program in the school curriculum, i.e., available to most students [10]. Although most physical education programs focus on children's physical health, further attention has been given to the possible cognitive benefits [11].

Previous studies have examined the beneficial effects of physical activity and physical fitness on cognitive functions [12]. To achieve this beneficial effect, the physical load is an essential factor that places a greater emphasis on aerobic activity [13]. Accordingly, some studies reported that aerobic fitness is associated with better cognitive functions [4, 14, 15]. For example, improved aerobic fitness in a sample of 13-year-old Spanish students was correlated with enhanced overall cognitive functions [16]. The point of such studies is that most of the research conducted in a laboratory environment has only focused on physiological mechanisms.

Another mechanism that might explain the impact of physical activity on cognitive functions is that motor skills require many of the same brain regions as do higher-level cognitive processes [17]. Perhaps studies of the effects of physical activity on cognitive functions should focus more on motor coordination and balance [18-21]. Training motor coordination may improve cognitive functions [22]. Executive functions are critical for school success, indeed Bittmann et al. found they could discriminate good students from poorer ones with $80 \%$ accuracy based on their balancing skills alone [23].

Research findings indicated that different mentioned physical activities may result in changes in the brain functions and sometimes brain structures [24]; however, some researchers believe that lack necessarily leads to improved executive functions in real contexts [6]. These researchers believe that to improve the benefits of physical activity for cognition, physical exercise should contain cognitive challenges $[6,25]$. Accordingly, exercise presents beneficial effects on brain function; however, to recognize demonstrable cognitive benefits, perhaps the exercise needs to be cognitively, as well as physically, demanding. This perspective on the improvement of cognitive functions through exercise is also emphasized by the hypothesis of cognitive stimulation $[11,26,27]$.

Most sports, in addition to physical challenges, require numerous executive functions (e.g., planning, attention, memory, inhibition, keeping goals in mind, adapting to changing environments, \& decision-making). Consequently, individuals implicitly practice executive functions by performing open skill sports [28]. However, the types of cognitive components (e.g., working memory or inhibition) as well as the difficulty and complexity of stimuli in the sport contexts (cognitive load) are usually presented randomly. Moreover, they are not completely under the control of the instructor, while the overload principle is among the main concepts in exercise science.

Although the hypothesis of combining physical exercise with cognitive training sounds appealing, the question then arises as to what kind of physical and cognitive components to combine. Several studies have addressed this issue with different protocols; however, the general paradigm in the area of physical training includes aerobic $[13,29]$ and perceptual-motor training programs (coordination \& balance) $[18,30]$. Furthermore, the core of most cognitive training focuses on working memory [31]. Studies of physical activity have often considered effects on other executive functions. For example, Tomporowski et al. focused on task switching and inhibition as well as the updating component of working memory [27]. Schmidt et al. argued that physical exercise with high Cognitive Engagement (CE), compared to similar physical exercise with low CE improved task switching, but not updating or inhibition [11].

Changing the cognitive paradigms used in the combination of cognitive training and physical exercise, or changing the cognitive demands of the physical activity, will most probably change the aspects of the affected cognition [32]. The present study aimed to investigate the effects of integrative physical and cognitive exercise on executive functions, compared to other physical exercises with low cognitive engagement. We increased the cognitive demands of physical exercise through common protocols of cognitive training. The physical activities posed physical and cognitive challenges; cognitive challenges were added to aerobic, balance, and coordinative exercise. Additionally, due to the importance of the school curriculum in the formation of health-related activities, school-based exercises were used.

\section{Materials and Methods}

In total, 47 students aged 13-14 years voluntarily participated in the current study. All research participants were right-handed and had no history of a medical condition. Informed written consent forms were obtained from all research participants. All procedures performed in studies involving human participants were 
per the ethical standards of the Allameh Tabataba'i University Research Committee. The study participants were randomly divided into 3 groups, as follows: Integrated Physical and Cognitive (IPC) exercise, physical exercise alone (with the same physical challenge), and a control group, which participated in the routine physical education program. The Continuous Performance Test (CPT), N-back, and Stroop tests were used to evaluate sustained attention, working memory, and inhibitory control, respectively.

In our visual continuous performance test [33], 400 stimuli divided into two categories (Go/No-Go) were presented to the study participants. For Go, stimuli subjects were to press the key on a computer keyboard. Failure to respond to a Go stimulus constituted an omission error. For No-Go stimuli, the study participants were not to do anything. Pressing the computer key for a No-Go stimulus constituted a commission error. The order of presentation of the stimuli was random. Dependent measures included omission and commission errors, reaction time, and reaction time variability.

The N-back test was used to evaluate working memory [34]. In this test, several visual stimuli were serially displayed on the screen; the individual had to press the target key if any stimulus was similar to the two previous stimuli. This task performs two main working memory operations, as follows: storing information, then updating it continuously. New information was simultaneously and instantaneously analyzed, compared with prestored information, and guided decision making. The error and correct percentages were evaluated as performance accuracy; while reaction time and its variability index were evaluated as information processing speed.

A computerized version of the Stroop test was used to evaluate the interference control and inhibition [35]. The 4 colors (green, yellow, blue, \& red) were used in this test, identified using color labels on the corresponding keys. In this test, the stimuli were divided into compatible and non-compatible categories, i.e., randomly presented during task execution. In compatible trials, the name and color of displayed words were similar (i.e., the word blue is displayed in blue), and in incompatible trials, the color name was contrasted with the displayed color (e.g., the word blue was shown in yellow). In both of these trails, one has to respond to the word color regardless of the meaning of the word. In this test, the number of errors and correct responses and reaction time in compatible and incompatible trials, interference score (difference between the number of errors in compatible $\&$ incompatible trails), and interference time (reaction time difference between compatible \& incompatible trails) were recorded.

In the first session, after explaining the experiment process, all subjects participated in the pretest. Then, the study participants in each group practiced in 3 different interventions (low or high cognitive engagement training \& the routine physical education class) for 8 weeks (16 sessions). All training groups performed two 60-minute training sessions per week. The first and last 10 minutes of each session were devoted to warm-up and cool-down; approximately 40-45 minutes were devoted to the main activity per session. In the routine physical education program (control group), in addition to warm-up and cool-down, they practiced physical fitness, volleyball, and basketball; however, different training programs were performed in the other two groups. Physical challenges were attempted to be almost similar in these two groups; the only difference between the study groups was in using cognitive paradigms.

During the training, both study groups encountered bio-motor challenges, such as balance, coordinated movements, and aerobic exercise with a high-intensity interval game approach; however, in the IPC group, cognitive challenges were combined with physical ones. The cognitive paradigms used in the IPC group included digit-forward, digit-backward, N-back, Switching, Stroop, and Go/ No- Go like tasks. Additionally, the aiming tasks were used for focused attention. For example, participants in the IPC group solved a puzzle while running, or they had to remember the sequence of movements according to the color of the cones while performing coordination steps on the agility ladder. At the end of the exercise sessions, the Stroop, N-back, and Continuous Performance Tests were re-administered. For data analysis, the two-way repeated-measures Analysis of Variance (ANOVA) was used to investigate the trend of the changes in groups induced by different interventions.

\section{Results}

Table 1 presents the results of the CPT test in different groups and test stages. The results of two-way repeatedmeasures ANOVA in omission error revealed a significant main effect of group $\left(F_{2,44}=3.65, P=0.034, \eta^{2}=0.14\right)$; however, the main effect of the test was not significant $\left(F_{1,44}=0.57, P=0.45, \eta^{2}=0.01\right)$. Moreover, no statistically significant difference was observed between the study groups concerning tests $\left(F_{2,44}=2.98, P=0.06, \eta^{2}=0.12\right)$.

In commission error component, the main effect of test $\left(F_{1,44}=3.55, P=0.06, \eta^{2}=0.07\right)$, the main effect of 
Table 1. Mean $\pm S D$ values of the CPT sub-tests

\begin{tabular}{cccccc}
\hline \multirow{2}{*}{ Tests } & Groups & \multicolumn{3}{c}{ Mean \pm SD } \\
\cline { 3 - 6 } & & Omission Error & Commission Error & Reaction Time & Reaction Time Variability \\
\hline \multirow{2}{*}{ Pretest } & IPC & $13.83 \pm 12.31$ & $64.85 \pm 43.43$ & $414.75 \pm 78.5$ & $114.54 \pm 25.82$ \\
& Physical & $19.65 \pm 16.38$ & $64.56 \pm 43.79$ & $397.91 \pm 68.9$ & $125.75 \pm 39.62$ \\
& Control & $10.85 \pm 11.4$ & $51.08 \pm 31.82$ & $381.42 \pm 81.01$ & $101.46 \pm 37.49$ \\
Posttest & IPC & $8.35 \pm 14.6$ & $44.8 \pm 51.6$ & $390.1 \pm 64.15$ & $121.79 \pm 39.74$ \\
& Physical & $29.7 \pm 31.6$ & $58.33 \pm 37.3$ & $415.72 \pm 69.65$ & $360.53 \pm 64.66$ \\
\hline
\end{tabular}

Exercise Science and Medicine

group $\left(F_{2,44}=0.5, P=0.6, \eta^{2}=0.02\right)$, and the interaction effect $\left(F_{2,44}=0.64, P=0.533, \eta^{2}=0.028\right)$ were also nonsignificant. The results of reaction time revealed that the main effect of the test $\left(F_{1,44}=1.5, P=0.22, \eta^{2}=0.03\right)$ and the main effect of group $\left(F_{2,44}=1.3, P=0.27, \eta^{2}=0.05\right)$ were not significant; however, there was a significant interaction between groups and tests $\left(F_{2,44}=3.29, P=0.04\right.$, $\left.\eta^{2}=0.13\right)$. The IPC reduced reaction time during the test stages; however, this reduction was not observed in the physical group. In the standard deviation of reaction times, the main effect of group $\left(F_{2,44}=1.4, P=0.25\right.$, $\left.\eta^{2}=0.06\right)$, the main effect of test $\left(F_{1,44}=0.69, P=0.41\right.$, $\left.\eta^{2}=0.01\right)$, and the interaction effect $\left(F_{2,44}=2.5, P=0.09\right.$, $\eta^{2}=0.1$ ) were not significant.

Table 2 illustrates the results of the N-back test in different groups and test stages. The results of the correct response percentage showed that the main effect of the group $\left(F_{2,44}=0.89, P=0.41, \eta^{2}=0.04\right)$ and the main effect of the test $\left(F_{1,44}=0.78, P=0.38, \eta^{2}=0.017\right)$ were not signif- icant. However, the trend of the change in groups during the test stages was significantly different $\left(F_{2,44}=4.16\right.$, $\left.\mathrm{P}=0.02, \eta^{2}=0.16\right)$. Accordingly, the IPC group had more progress than the other groups.

In the reaction time of the $\mathrm{N}$-back test, the main effect of group $\left(F_{2,44}=0.23, P=0.79, \eta^{2}=0.01\right)$ and interaction effect $\left(F_{2,44}=2.7, P=0.07, \eta^{2}=0.11\right)$ were not significant; however, the results indicated that the main effect of the test was significant $\left(F_{1,44}=16.19, P=0.0001\right.$, $\left.\eta^{2}=0.27\right)$. Accordingly, all training groups in this component manifested the same improvement. Additionally, the analysis of standard deviation of reaction time in $\mathrm{N}$-back test revealed that the main effect of group $\left(\mathrm{F}_{2}\right.$ $\left.{ }_{44}=0.97, P=0.39, \eta^{2}=0.04\right)$, the main effect of the test $\left(F_{1}\right.$ $\left.{ }_{44}=0.008, P=0.92, \eta^{2}=0.0001\right)$, and the interaction effect $\left(F_{2,44}=1.47, P=0.23, \eta^{2}=0.06\right)$ was also not significant.

The results of the Stroop test are listed in Table 3. The interference score revealed that the main effect of

Table 2. Mean \pm SD scores of the N-back sub-tests

\begin{tabular}{rrrrr}
\hline \multirow{2}{*}{ Tests } & Groups & & \multicolumn{1}{c}{ Mean \pm SD } & \\
\cline { 3 - 5 } & & Correct Response Percentage & Reaction Time & Reaction Time Variability \\
\hline \multirow{3}{*}{ Pretest } & IPC & $56.94 \pm 10.31$ & $707.94 \pm 240.12$ & $294.81 \pm 97.51$ \\
& Physical & $56.75 \pm 13.85$ & $778.25 \pm 219.71$ & $330.75 \pm 77.11$ \\
& Control & $65.4 \pm 15.57$ & $729.0 \pm 154.33$ & $296.26 \pm 58.74$ \\
& IPC & $67.81 \pm 12.33$ & $694.75 \pm 217.74$ & $230.5 \pm 71.99$ \\
\multirow{3}{*}{ Posttest } & Physical & $57.43 \pm 19.0$ & $670.06 \pm 185.08$ & $266.87 \pm 87.73$ \\
& Control & $60.0 \pm 19.49$ & $629.46 \pm 103.95$ & $439.8 \pm 69.58$ \\
\hline
\end{tabular}


Table 3. Mean $\pm S D$ scores of the Stroop sub-tests

\begin{tabular}{|c|c|c|c|}
\hline \multirow{2}{*}{ Tests } & \multirow{2}{*}{ Groups } & \multicolumn{2}{|c|}{ Mean $\pm S D$} \\
\hline & & Interference Score & Interference Time \\
\hline \multirow{3}{*}{ Pretest } & IPC & $0.06 \pm 1.28$ & $26.38 \pm 37.57$ \\
\hline & Physical & $1.06 \pm 1.29$ & $24.81 \pm 35.94$ \\
\hline & Control & $0.2 \pm 1.08$ & $37.67 \pm 41.65$ \\
\hline \multirow{3}{*}{ Posttest } & IPC & $0.56 \pm 0.96$ & $29.87 \pm 34.34$ \\
\hline & Physical & $0.43 \pm 1.15$ & $30.93 \pm 32.44$ \\
\hline & Control & $0.2 \pm 1.2$ & $25.2 \pm 39.95$ \\
\hline
\end{tabular}

group $\left(F_{2,44}=2.9, P=0.06, \eta^{2}=0.11\right)$, the main effect of test $\left(F_{1,44}=0.41, P=0.35, \eta^{2}=0.008\right)$, and the interaction effect $\left(F_{2,44}=3.01, P=0.06, \eta^{2}=0.12\right)$ were not significant.

Similar results were observed in the interference time in the Stroop test, suggesting that the main effect of group $\left(F_{2,44}=0.08, P=0.91, \eta^{2}=0.06\right)$, the main effect of the test $\left(F_{1,44}=0.016, P=0.9, \eta^{2}=0.0001\right)$, and interaction effect $\left(F_{2,44}=0.58, P=0.56, \eta^{2}=0.02\right)$ were not significant.

\section{Discussion}

The current study investigated the effects of 3 schoolbased physical exercises with different cognitive loads on executive functions. Accordingly, participants in 3 groups practiced different types of physical exercise. The relevant results indicated that the Integrated Physical and Cognitive exercise (IPC) group significantly improved, compared to the other groups in terms of the reaction time of the CPT test. The reaction time of CPT reflected the processing speed of targeted stimuli or stimuli that participants must respond to them. The collected results indicated that the omission and commission errors were not affected by the exercises; however, the different improvement was observed only in the reaction time of CPT. Previous studies signified that the effect of physical exercise on response accuracy and speed was different [36]. Therefore, there was a more positive effect on reaction time than response accuracy, i.e., in line with the findings of McMorris et al., indicating that physical exercise is more likely to influence the reaction time [36]. Furthermore, the result of the $\mathrm{N}$ back test reflected that the physical exercise group with a higher cognitive load had more progress in response accuracy, compared to the other groups; however, the improvement in the reaction time of the $\mathrm{N}$-back test was observed in all groups. Therefore, the current research results demonstrated that different exercise types affected the response accuracy or speed.

The obtained data supported the combination of physical and cognitive challenges in improving cognitive functions and specifically in the subtests of the N-back test and CPT. These findings were in line with those indicating that the qualitative dimension of physical training is as crucial as its quantitative dimension [25]. Accordingly, the effects of cognitive training along with physical exercise can be merged, leading to improving its effects [37]. Diamond and Ling believe that "aerobic training, or resistance training, without cognitive challenges, does little or no benefit to executive functions". According to some studies, sports and physical exercises that require mental engagement, such as traditional martial arts, yoga, tai chi, etc., can help improve executive functions [6]. Pesce et al. suggested that the attention of typically developing children improved when physical activity was combined with cognitive challenges [26]. In a study conducted on obese children aged 9-10 years, the results revealed that physical activity combined with cognitive challenges improved cognitive functions, compared to routine physical education programs [38]. However, some researchers cautioned against making decisions based on this small number of studies [39]. The present study findings reflected that combined exercise (IPC group) improved sustained attention and updating.

In addition, the results of the N-back test suggested that reaction time was improved in different types of exercise. Research has also indicated that different types of exercise, regardless of qualitative or cognitive dimension, can also improve some cognitive functions. Hillman et al., in a review study, stated that motor skills 
and exercise, even when the cognitive load is low, can improve executive functions. This is because of their effects on brain structures that can affect cognitive functions [29]. Accordingly, executive functions largely depend on the activity of specific areas of the brain. The executive functions are mainly related to the Prefrontal Cortex (PFC) and other neural regions. In this regard, evidence highlighted that the intervention that affects the PFC may also influence executive functions [29]. Therefore, following physical activity and motor skills training, these areas are affected even when the cognitive load is low. Additionally, neurophysiological mechanisms may be effective for explaining the effect of physical exercise regardless of cognitive load. Increased blood flow and oxygen supply to the brain as well as increased levels of BDNF can be attributed to the mechanisms of improvement through these exercises [40].

Some research suggested that adding physical exercise to cognitive training does not provide additional benefits to executive functions [41]. Our findings were consistent with these results, which may be due to improved reaction time, regardless of the type of exercise; however, due to the different progression of the combined group (IPC), compared to other groups; the present findings may be inconsistent with those of the above-mentioned studies.

Our results may be in contrast with those of Schmidt et al., suggesting that updating in children and adolescents has rarely changed as a result of physical exercise [11]. However, the present study findings revealed an improvement in the $\mathrm{N}$-back test, which examined the updating performance. These results can be considered based on the contents of the cognitive challenges. In the current study, much of the cognitive challenges used in physical exercise were related to working memory-like tasks. The digit-forward, digit-backward paradigms, task-switching, and updating-like tasks were more related to working memory. Besides, the Stroop and Go-Nogo-like tasks seem to use working memory [42]. These results can be considered from the transfer perspective of cognitive training. Based on studies conducted, cognitive training can have narrow and near transfer $[2,6]$.

In the study by Schmidt et al., although they used inhibition and updating patterns in the design of the exercise, they placed further emphasis on the switching component due to the nature of the sports games. This may be due to the near-transfer effect, this component was affected more than others. Accordingly, further effects are observed in tasks that have similar processing needs, such as N-back, and the transfer of its effects to interference control is difficult [32]. It is therefore recommended that future research requires to focus on investigating the separate and combined effects of different cognitive challenges and physical exercise. The results of the Stroop test also revealed no significant difference between the research groups concerning the interference control component and interference time component. Thus, the type of exercise could not provide a different effect on the progression in interference control.

In line with our findings, Schmidt et al. observed no effect of different physical exercises on inhibition control. Accordingly, the inhibitory control may well evolve in children; therefore, it may be less readily affected [43]. On the other hand, some studies reflected that inhibition control can be affected [44].

In the combination of physical and cognitive challenges, it seems necessary to mention a few limitations, as follows: First, the issue of real cognitive versus artificial cognitive load. Based on this, real sports activities, such as tennis, soccer, and other sports seem to have various cognitive challenges in addition to physical challenges that can be created and fun. However, the worthwhile point to consider in these exercises is that the cognitive load in these sports fields, cannot be gradually controlled by the coach, while controlling exercise components is among the principles of exercise design. Therefore, this challenging trade-off between actual and artificial cognitive challenges and control of them will continue.

Accordingly, in the present study, in addition to controlling the cognitive load of the exercise, we attempted to use cognitive tasks close to the real environment. Notable, the control of both challenges of the control of cognitive components and the similarity of cognitive tasks with the real environment is not completely possible. Another limitation facing the combination of physical exercise with cognitive challenges may be that the focus of the performer on cognitive challenges may cause the quality of performing motor skills to be neglected and not practiced and this will reduce the beneficial effects of physical exercise. However, the performance accuracy was assessed by the trainers. In addition, cognitive challenges may reduce the enjoyment of physical exercise, while enjoyment is a key prerequisite for improving cognitive functions through exercise [8]; however, with a game-based approach, this problem was tried to be minimized. 


\section{Conclusion}

Overall, our findings demonstrated that positive effects of the cognitive functions were observed in integrated physical and cognitive exercise; however, these benefits were only observed in working memory and attention components. Since the IPC exercise placed more emphasis on working memory training paradigms, this component was most affected by this exercise. Furthermore, there seems to be a close relationship between working memory and attention interventions. The physical exercise with higher cognitive load affected both the performance speed and accuracy of cognitive tasks, while physical training with low cognitive engagement had only a positive effect on the component of speed. Overall, our study can be considered as empirical evidence of the benefits of physical and cognitive training combination. In this regard, there seems no intervention that can improve all cognitive dimensions, and each activity type can improve its related dimension. Therefore, further research is necessary to investigate it.

\section{Ethical Considerations}

\section{Compliance with ethical guidelines}

The present study was accordance with the ethical standards of Allameh Tabataba'i University research committee. Also, written informed consent was obtained from all the participants

\section{Funding}

This study received no grant from any institution/company/university. The manuscript is taken from MSc. thesis of the first author.

\section{Authors' contributions}

Conceptualization: Methodology: all author; Investigation: Shohre Mardasangi Dulabi; Writing - original draft: Shohre Mardasangi Dulabi, Mohammdreza Ghasemian; Writing - review \& editing: Shohre Mardasangi Dulabi, Mohammdreza Ghasemian; Supervision: Mohammdreza Ghasemian, Mohammadali Aslankhani.

\section{Conflict of interest}

The authors declared no potential conflicts of interest.

\section{Acknowledgments}

The authors would like to thank all students and teachers who participated in this study accurately and kindly.

\section{References}

[1] Hodges JR. Cognitive assessment for clinicians. Oxford: Oxford University Press; 2017. https://books.google.com/ books?id=QYcODwAAQBAJ\&dq

[2] Diamond A. Executive functions. Annual Review of Psychology. 2013; 64:135-68. [DOI:10.1146/annurev-psych-113011-143750] [PMID] [PMCID]

[3] Luna B. Developmental changes in cognitive control through adolescence. Advances in Child Development and Behavior. 2009; 37:233-78. [DOI:10.1016/S0065-2407(09)03706-9] [PMID] [PMCID]

[4] Westfall DR, Gejl AK, Tarp J, Wedderkopp N, Kramer AF, Hillman CH, et al. Associations between aerobic fitness and cognitive control in adolescents. Frontiers in Psychology. 2018; 9:1298. [DOI:10.3389/ fpsyg.2018.01298] [PMID] [PMCID]

[5] Diamond A. Activities and programs that improve children's executive functions. Current Directions in Psychological Science. 2012 21(5):335-41. [DOI:10.1177/0963721412453722] [PMID] [PMCID]

[6] Diamond A, Ling DS. Conclusions about interventions, programs, and approaches for improving executive functions that appear justified and those that, despite much hype, do not. Developmental Cognitive Neuroscience. 2016; 18:34-48. [DOI:10.1016/j. dcn.2015.11.005] [PMID] [PMCID]

[7] Diamond A, Ling DS. Review of the evidence on, and fundamenta questions about, efforts to improve executive functions, including working memory. In: Novick JM, Michael F. Bunting, Dougherty MR, Engle RW. Cognitive and Working Memory Training: Perspectives From Psychology, Neuroscience, And Human Development. Oxford: Oxford University Press; 2019. p. 143-431. [DOI:10.1093/ oso/9780199974467.003.0008]

[8] Diamond A. Effects of physical exercise on executive functions: Going beyond simply moving to moving with thought. Annals of Sports Medicine and Research. 2015; 2(1):1011. [PMID] [PMCID]

[9] Diamond A, Ling DS. Aerobic-exercise and resistance-training interventions have been among the least effective ways to improve executive functions of any method tried thus far. Developmental Cognitive Neuroscience. 2019; 37:100572. [DOI:10.1016/j. dcn.2018.05.001] [PMID] [PMCID]

[10] Tarp J, Domazet SL, Froberg K, Hillman CH, Andersen LB, Bugge A. Effectiveness of a school-based physical activity intervention on cognitive performance in Danish adolescents: LCoMotion-learning, cognition and motion-a cluster randomized controlled trial. PloS One. 2016; 11(6):e0158087. [DOI:10.1371/journal.pone.0158087] [PMID] [PMCID]

[11] Schmidt M, Jäger K, Egger F, Roebers CM, Conzelmann A. Cognitively engaging chronic physical activity, but not aerobic exercise, affects executive functions in primary school children: A group-randomized controlled trial. Journal of Sport and Exercise Psychology. 2015; 37(6):575-91. [DOI:10.1123/jsep.2015-0069] [PMID]

[12] Erickson KI, Hillman CH, Kramer AF. Physical activity, brain, and cognition. Current Opinion in Behavioral Sciences. 2015; 4:27-32. [DOI:10.1016/j.cobeha.2015.01.005]

[13] Best JR. Effects of physical activity on children's executive function: Contributions of experimental research on aerobic exercise. Developmental Review. 2010; 30(4):331-51. [DOI:10.1016/j. dr.2010.08.001] [PMID]

[14] Ahn S, Fedewa AL. A meta-analysis of the relationship between children's physical activity and mental health. Journal of Pediat- 
ric Psychology. 2011; 36(4):385-97. [DOI:10.1093/jpepsy/jsq107] [PMID]

[15] Hillman CH, Castelli DM, Buck SM. Aerobic fitness and neurocognitive function in healthy preadolescent children. Medicine and Science in Sports and Exercise. 2005; 37(11):1967-74. [DOI:10.1249/01.mss.0000176680.79702.ce] [PMID]

[16] Raine LB, Biggan JR, Baym CL, Saliba BJ, Cohen NJ, Hillman CH. Adolescent changes in aerobic fitness are related to changes in academic achievement. Pediatric Exercise Science. 2018; 30(1):106-14 [DOI:10.1123/pes.2015-0225] [PMID]

[17] Diamond A. Close interrelation of motor development and cognitive development and of the cerebellum and prefrontal cortex. Child Development. 2000; 71(1):44-56. [DOI:10.1111/1467-8624.00117] [PMID]

[18] Budde H, Voelcker-Rehage C, Pietraßyk-Kendziorra S, Ribeiro $P$, Tidow G. Acute coordinative exercise improves attentional performance in adolescents. Neuroscience Letters. 2008; 441(2):219-23. [DOI:10.1016/j.neulet.2008.06.024] [PMID]

[19] Rigoli D, Piek JP, Kane R, Oosterlaan J. An examination of the relationship between motor coordination and executive functions in adolescents. Developmental Medicine \& Child Neurology. 2012; 54(11):1025-31. [DOI:10.1111/j.1469-8749.2012.04403.x] [PMID]

[20] Haynes W, Waddington G, Adams RD. Associations among balance, physical activity, physical fitness, and academic results in schoolchildren. Health Behavior and Policy Review. 2018; 5(1):5768. [DOI:10.14485/HBPR.5.1.6]

[21] Mihara M, Miyai I, Hatakenaka M, Kubota K, Sakoda S. Role of the prefrontal cortex in human balance control. Neuroimage. 2008; 43(2):329-36. [DOI:10.1016/j.neuroimage.2008.07.029] [PMID]

[22] Liu JH, Alderman BL, Song TF, Chen FT, Hung TM, Chang YK. A randomized controlled trial of coordination exercise on cognitive function in obese adolescents. Psychology of Sport and Exercise. 2018; 34:29-38. [DOI:10.1016/j.psychsport.2017.09.003]

[23] Bittmann FN, Gutschow S, Luther S, Wessel N, Kurths J. On the functional relationship between postural motor balance and performance at school. Deutsche Zeitschrift für Sportmedizin. 2005 56(10):348-52. https://publishup.uni-potsdam.de/frontdoor/index/index/docld/13501

[24] Hillman CH, Erickson KI, Kramer AF. Be smart, exercise your heart: exercise effects on brain and cognition. Nature Reviews Neuroscience. 2008; 9(1):58-65. [DOI:10.1038/nrn2298] [PMID]

[25] Pesce C. Shifting the focus from quantitative to qualitative exercise characteristics in exercise and cognition research. Journal of Sport and Exercise Psychology. 2012; 34(6):766-86. [DOI:10.1123/ jsep.34.6.766] [PMID]

[26] Pesce C, Crova C, Marchetti R, Struzzolino I, Masci I, Vannozzi G, et al. Searching for cognitively optimal challenge point in physical activity for children with typical and atypical motor development. Mental Health and Physical Activity. 2013; 6(3):172-80 [DOI:10.1016/j.mhpa.2013.07.001]

[27] Tomporowski PD, McCullick B, Pendleton DM, Pesce C. Exercise and children's cognition: The role of exercise characteristics and a place for metacognition. Journal of Sport and Health Science. 2015; 4(1):47-55. [DOI:10.1016/j.jshs.2014.09.003]

[28] Oberer N, Gashaj V, Roebers CM. Executive functions, visual-motor coordination, physical fitness and academic achievement: Longitudinal relations in typically developing children. Human Move- ment Science. 2018; 58:69-79. [DOI:10.1016/j.humov.2018.01.003] [PMID]

[29] Hillman CH, McAuley E, Erickson KI, Liu-Ambrose T, Kramer AF On mindful and mindless physical activity and executive function: A response to Diamond and Ling (2016). Developmental Cognitive Neuroscience. 2019; 37:100529. [DOI:10.1016/j.dcn.2018.01.006] [PMID] [PMCID]

[30] Luz C, Rodrigues LP, Cordovil R. The relationship between motor coordination and executive functions in 4 th grade children. European Journal of Developmental Psychology. 2015; 12(2):129-41. [D OI:10.1080/17405629.2014.966073]

[31] Novick JM, Bunting MF, Dougherty MR, Engle RW. Cognitive and working memory training: Perspectives from psychology, neuroscience, and human development. Oxford Scholarship Online. 2020. [DOI:10.1093/oso/9780199974467.001.0001]

[32] Covey TJ, Shucard JL, Shucard DW. Working memory training and perceptual discrimination training impact overlapping and distinct neurocognitive processes: Evidence from event-related potentials and transfer of training gains. Cognition. 2019; 182:50-72. [DOI:10.1016/j.cognition.2018.08.012] [PMID]

[33] Riccio CA, Reynolds CR, Lowe PA. Clinical applications of continuous performance tests: Measuring attention and impulsive responding in children and adults. Hoboken: Wiley; 2001. https:// books.google.com/books?id=hq5rAAAAMAAJ\&q

[34] León-Domínguez U, Martín-Rodríguez JF, León-Carrión J. Executive n-back tasks for the neuropsychological assessment of working memory. Behavioural Brain Research. 2015; 292:167-73. [DOI:10.1016/j.bbr.2015.06.002] [PMID]

[35] Gorfein DS, MacLeod CM, MacLeod CM. Inhibition in cognition Washington DC: American Psychological Association; 2007. https:// books.google.com/books?id=M19qAAAAMAAJ\&q

[36] McMorris T, Sproule J, Turner A, Hale BJ. Acute, intermediate intensity exercise, and speed and accuracy in working memory tasks: A meta-analytical comparison of effects. Physiology \& Behavior. 2011; 102(3-4):421-8. [DOI:10.1016/j.physbeh.2010.12.007] [PMID]

[37] Ward N, Paul E, Watson P, Cooke GE, Hillman CH, Cohen NJ, et al. Enhanced learning through multimodal training: Evidence from a comprehensive cognitive, physical fitness, and neuroscience intervention. Scientific Reports. 2017; 7(1):5808. [DOI:10.1038/s41598017-06237-5] [PMID] [PMCID]

[38] Crova C, Struzzolino I, Marchetti R, Masci I, Vannozzi G, Forte R et al. Cognitively challenging physical activity benefits executive function in overweight children. Journal of Sports Sciences. 2014; 32(3):201-11. [DOI:10.1080/02640414.2013.828849] [PMID]

[39] Northey JM, Cherbuin N, Pumpa KL, Smee DJ, Rattray B. Exercise interventions for cognitive function in adults older than 50: A systematic review with meta-analysis. British Journal of Sports Medicine. 2018; 52(3):154-60. [DOI:10.1136/bjsports-2016-096587] [PMID]

[40] Drollette ES, Pontifex MB, Raine LB, Scudder MR, Moore RD, Kao SC, et al. Effects of the FITKids physical activity randomized controlled trial on conflict monitoring in youth. Psychophysiology. 2018; 55(3):e13017. [DOI:10.1111/psyp.13017] [PMID] [PMCID]

[41] Moreau D, Morrison AB, Conway AR. An ecological approach to cognitive enhancement: Complex motor training. Acta Psychologica. 2015; 157:44-55. [DOI:10.1016/j.actpsy.2015.02.007] [PMID] 
[42] Barbey AK, Koenigs M, Grafman J. Dorsolateral prefrontal contributions to human working memory. Cortex. 2013; 49(5):1195-205. [DOI:10.1016/j.cortex.2012.05.022] [PMID] [PMCID]

[43] Davidson MC, Amso D, Anderson LC, Diamond A. Development of cognitive control and executive functions from 4 to 13 years: Evidence from manipulations of memory, inhibition, and task switching. Neuropsychologia. 2006; 44(11):2037-78. [DOI:10.1016/j.neuropsychologia.2006.02.006] [PMID] [PMCID]

[44] Kao S-C, Drollette ES, Ritondale JP, Khan N, Hillman CH. The acute effects of high-intensity interval training and moderate-intensity continuous exercise on declarative memory and inhibitory control. Psychology of Sport and Exercise. 2018; 38:90-9. [DOI:10.1016/j. psychsport.2018.05.011] 
This Page Intentionally Left Blank 